\title{
Modeling environmental responses of plant associations by fuzzy set theory
}

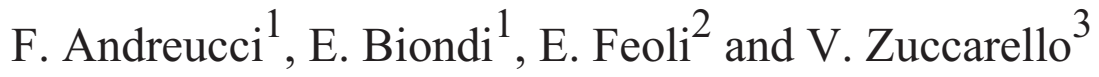 \\ ${ }^{1}$ Department of Agricultural and Environmental Biotechnology, University of Ancona, via Brecce bianche, \\ I- 62032 Ancona, Italy.E-mail: biondi@popcsi.unian.it \\ ${ }^{2}$ Department of Biology, University of Trieste, via Giorgeri 5 , \\ I-34100 Trieste, Italy.E-mail: feoli@univ.trieste.it \\ ${ }^{3}$ Department of Environmental Science, University of Ca' Foscari Venezia, Campo Celestia 2737b, \\ I-30122Venezia, Italy.E-mail: zuc@unive.it
}

Keywords: Fuzzy sets, Halophilous vegetation, Italy, Northern Adriatic coasts, Phytosociology, Synecology.

\begin{abstract}
A method for studying the response of vegetation to environmental gradients, based on the community niche and fuzzy set theory, is presented. The approach is illustrated using an example from perennial halophilous vegetation along the Northern Adriatic coast of Italy. Compatibility curves are obtained by fuzzy set theoretical methods, and are used to model the response functions of plant associations to environmental gradients, including soil and ground water salinity, soil $\mathrm{pH}$, soil and ground water temperature, percentage of sand, and variations in the ground water level. The compatibility curves summarize the similarity of a given plant community, with a particular value of an environmental variable, to the species combination of a given plant association. Compatibility curves offer an alternative approach to non-linear regression and best fit analyses normally used to model single species responses to environmental gradients. The approach is particularly useful given there is no single mechanistic model that can capture the exact shape of the functional response along environmental gradients, and given that environmental data are commonly affected by high levels of noise.
\end{abstract}

Abbrevia tions: ECs - electric conductivity of soil, ECw - electric conductivity of the ground water, PHs - soil pH, Ts - soil temperature, $\mathrm{Tw}$ - ground water temperature, Hw - variation of the groundwater level, Sand\% - percentage of sand in the soil, Pucc. Halim Puccinellio festuciformis-Halimionetum portulacoidis, Pucc.Sarc - Puccinellio festuciformis-Sarcocornietum fruticosae, Pucc.Arth Puccinellio convolutae-Arthrocnemetum macrostachyi, Arth.Halo - Arthrocnemo macrostachyi-Halocnemetum strobilacei.

\section{Introduction}

Despite its simplicity and usefulness in synecological studies, the community niche concept is largely neglected in vegetation and landscape ecological surveys. The community niche concept gives logical consistency to measures of beta-diversity (Whittaker 1967, 1975) along gradients and in multidimensional space (Feoli et al. 1988). Early examples of direct approaches to analyzing the ecological response of plant associations (e.g., the number of characteristic species expressed as a function of a specified ecological factor) can be found in Braun Blanquet (1964) and Pirola (1959). The concept of community niche can be used either non-explicitly (e.g., to produce vegetation maps of Switzerland, Brzeziecki et al. 1993) or explicitly (e.g., Egzhiabher et al. 1998). In this paper, we develop methods for modeling the response curves of plant associations along gradients using fuzzy set theory (Zadeh 1965, Zimmerman 1996). Our model is based on the similarity between relevés of different plant communities having well-defined plant associations (Feoli and Zuccarello 1988, Zuccarello et al. 1999).

\section{Vegetation concepts}

Some basic working definitions of plant community, plant association and community niche are required to explain the suggested approach (c.f. Feoli 1988):

1. Vegetation is sampled and described using relevés. A relevé is an attempt to describe in a satisfactory way a plant community at a given time in a given place. 
The variables are plant species, environmental chemical-physical factors, animal species, and socioeconomic variables that might potentially affect the vegetation. Relevés can be located following some statistical or preferential sampling design (Orlóci 1991a,b; Orlóci and De Patta Pillar 1991). A relevé is an initial description of the vegetation, usually in terms of species abundance values expressed as percentage cover or on an ordinal scale (see Mueller Dombois and Ellenberg 1974, Greig Smith 1983).

2. The plant community is a state of the vegetation system given by a combination of populations of different plant species living together in a homogeneous environment. Strictly speaking, the environment is considered homogeneous only if the states of chemical-physical variables follow a completely random spatial arrangement. The species characterizing the community persist if their ecological niche is met, if they are able to resist or adapt to changing conditions, if they are able to withstand the competition, and if they are not overexploited (grazed, harvested, etc.). Plant communities are combinations of species that can vary more or less gradually along gradients (ecoclines), or discontinuously across ecotones.

3. Plant communities whose relevés are considered similar enough are grouped into the same community type, termed a plant association in the BraunBlanquet approach (Westhoff and van der Maarel 1978). The plant association, which is the fundamental level in the hierarchical classification of the biosphere (Mueller Dombois and Ellenberg 1974, Walter 1979), is defined by a combination of differential characteristic species. A characteristic species of a plant association is statistically more frequent and/or abundant in that association than in other associations. By definition, the expected probability of finding two or more species together is lower than the probability of finding a single species. For this reason, a combination of species is always more informative than a single species (from information theory, see Feoli et al. 1984). Extending this argument, plant associations are more effective environmental indicators than single species.

4. A plant association is by definition distributed within the common geographic range of its characteristic species. The contiguity and shape of the area occupied by a plant association is therefore dependent on the contiguity of the environment niche of the set of its characteristic species. The hypervolume of the environmental conditions that hosts the plant association in multidimensional ecological space defines the community niche of the plant association (Feoli et al. 1988). Community niches may be wide or narrow, irrespective of the contiguity of the association's geographic space. What is relevant in defining the community niche is the common niche width of the characteristic species.

5. A plant association is a self-organizing system consisting of a combination of species that vary according to environmental variability, biogeographical history, disturbance and change in the dispersion processes, etc. While a plant association is defined by the characteristic species, it also includes many other species that are also found in other plant associations. These latter species are mainly responsible for the similarity of different associations, supporting the notion of the vegetation continuum as opposed to the community-unit theory (Whittaker 1975). The importance of the association concept relies on the associated idea of chemical-physical environmental homegeneity. Without this, the plant association concept would collapse.

\section{Materials and methods}

\section{Study area}

Data were collected from halophilous perennial vegetation of the Sacca di Bellocchio Nature Reserve in Ravenna province, Italy (Andreucci et al. 1999). The Sacca di Bellocchio is a coastal site on the northern Adriatic Sea between the Ferrara and Ravenna beaches. Halophilous vegetation extends over 250 hectares near the mouth of the Reno river. The site is delimited on the west by a line of paleo-dunes, on the south by the Casalborsetti pinewoods, on the north by the Gobino canal, and on the east by the Adriatic. Elevation ranges from about $1 \mathrm{~m}$ at the line of dunes paralleling the coast to a few centimeters below mean sea level in the internal depressions. The area is frequently flooded, and fine river sediments are redistributed by the tides. The hydromorphic soils, mostly composed of clays and organic marine materials, undergo reduction or iron segregation.

The study area is in the temperate macrobioclimate (Rivas-Martinez 1994, 1995). The hilly portion is in subhumid umbroclimate bioclimatic belt (Biondi and Baldoni 1994). The northern limit of the Mediterranean bioclimate is located at Monte Conero, just south of the study area.

\section{Vegetation data}

Relevés were located in the hypersaline sector in bowl-shaped depressions. The vegetation analysis (using 
Table 1. Phytosociological relevés of four halophilous plant associations.

\begin{tabular}{|c|c|c|c|c|c|c|c|c|c|c|c|c|c|c|c|c|c|c|c|c|c|c|c|c|c|c|c|c|c|c|c|c|c|}
\hline Association & & Puo & cc.t & Hall & & & & Puc & ec.S & Sar & & & & & & Puc & cc. & Arth & & & & & & & & & Art & h.H & lalo & & & & \\
\hline Relevé $n^{\circ}$ & 3 & 4 & 23 & 25 & 27. & 10 & 11 & 19 & 20 & 21 & 26 & 22 & 6 & 9 & 47 & 49 & 46 & 52 & 48 & 53 & 50 & 51 & 31 & 32 & 33 & 34 & 35 & 7 & 29 & 13 & 8 & 283 & 30 \\
\hline Aeluropus litoralis & 3 & 3 & & & & & & & & & & & & & & & & & & & & & & & & & & & & & & & \\
\hline Halimione portulacoides & 5 & 3 & 2 & 3 & 2 & & & 1 & 1 & & & & + & + & 1 & + & + & & 2 & 3 & 2 & 2 & & & & & & & & & & & \\
\hline Puccinellia festuciformis & + & 3 & 2 & 2 & 1 & 1 & + & + & + & + & + & & + & + & + & & 1 & + & 2 & 2 & 1 & + & & & & & & & & & & & \\
\hline Limonium narbonensis & 2 & 3 & 2 & 2 & 1 & 2 & 1 & 1 & & & & & & + & & & & 1 & 2 & 9 & & & & & & & & & & & & & \\
\hline Limonium bellidifolium & + & 2 & 1 & & & & & & & & & & & & & & & & + & & $i$ & & & & & & & & & & & & \\
\hline Inula crithmoides & + & & & + & & & & & & & & & & & & & & & & + & & 2 & & & & & & & & & & & \\
\hline Sarcocomia deflexa & & & & & & & & & & & & 1 & & 1 & & & 2 & & & & & & & & & 2 & & & & & & & \\
\hline Sarcornia fruticosa & 2 & 2 & 4 & 3 & 1 & 5 & 5 & 5 & 5 & 4 & 3 & 4 & & & 1 & & & & + & + & & & & 1 & 1 & & 2 & & & & & & \\
\hline Arthrocnemum macrostachyum & & 1 & + & & 1 & 1 & + & + & & & + & + & 4 & 4 & 5 & 5 & 5 & 3 & 5 & 3 & 5 & 4 & & & & & & 1 & 1 & 1 & 1 & & \\
\hline Halocnemum strobilaceum & & & & & & & & & 1 & & & & + & + & & 1 & & & & & & & 5 & 5 & 4 & 4 & 3 & 3 & 5 & 4 & 5 & 5 & 5 \\
\hline Suaeda maritima & 1 & + & & & 1 & & & + & & & & & 1 & + & & & & & & 1 & & & & & & & & & & & 1 & & \\
\hline Salicornia veneta & & & & & & 1 & 1 & & & 1 & & & & & & & & + & & & & & & & & & & & & + & + & & \\
\hline Agropyron elongatum & 1 & & & & & & & & & & & & & & & & & & & & & & & & & & & & & & & & \\
\hline Atriplex latifolia & & & & & & & & & & & & & & & & & & & & & + & & & & & & & & & & & & \\
\hline Agropyron pungens & & & & & & & & & & & & & & & & & & & & & & + & & & & & & & & & & & \\
\hline
\end{tabular}

the phytosociological method, see Andreucci et al. 1999) identified the following halophilous plant associations (Table 1) :

1) Puccinellio festuciformis-Halimionetum portulacoidis Gehu et al. 1992 (Pucc.Halim);

2) Puccinellio festuciformis-Sarcocornietum fruticosae (Br.-B1. 1928) Gehu 1976 (Pucc.Sarc);

3) Puccinellio convolutae-Arthrocnemetum macrostachyi [Br.-Bl. 1928) 1933] Gehu et al. 1984 (Pucc.Arth);

4) Arthrocnemo macrostachyi-Halocnemetum strobilacei Oberd. 1952 (Arth.Halo).

These associations are composed of a few highly specialized species. Halocnemum strobilaceum is of particular biogeographical and ecological importance, since it reaches the northern limits of its geographical distribution in the study area and the nearby Saline di Comacchio (Corbetta 1976, Biondi 1992 and Piccoli 1995). The vegetation data of Table 1 were used to derive two matrices, after transforming the Braun-Blanquet cover-abundance data to the van der Maarel scale (Westhoff and van der Maarel 1978). Matrix V contains species as rows and relevés as columns, whereas matrix $\mathbf{C}$ contains the centroids of the species as rows in the four plant associations as columns.

\section{Environmental data}

The environmental data set includes the following chemical-physical variables: electric conductivity of soil (ECs); electrical conductivity of the ground water (ECw); soil $\mathrm{pH}(\mathrm{pHs})$; soil temperature (Ts); ground water temperature (Tw); variation in groundwater level (Hw); percent sand in the soil (Sand\%). These data were collected for each association along transects perpendicular to the coastline from September 1993 to April 1995, at intervals of 28 days corresponding to the monthly high tide. Ground water data were obtained using piezometric tubes positioned along the transects. The environmental data were used to construct a matrix $\mathbf{E}$ of means for the seven chemical-physical variables as rows, in four plant associations as columns (Table 2).

\section{Data analysis}

Using matrix $\mathbf{V}$ and the matrix of centroids of the plant associations $\mathbf{C}$, the degree of 'belonging' of the relevés to each association is calculated by matrix multiplication $\mathbf{C}^{\prime} \mathbf{V}$. The resulting values were adjusted to range from 0 to 1 . The environmental fuzzy sets were obtained by matrix multiplication $\mathbf{E} \mathbf{C}^{\prime} \mathbf{V}=\mathbf{F}$ (Feoli and Zuccarello 1986, 1988, 1992), and then adjusted to range from 0 to 1. Matrix $\mathbf{F}$ is used to model the response function of each plant association to environmental gradients according to the following procedure:

1. Based on the entries of $\mathbf{F}\left(\mu\left(x_{i}\right)\right)$, the 'crisp' values associated with the individual relevés are obtained by defuzzification according to the formula:

$$
x_{i}=x_{\min }+\mu\left(x_{i}\right) *\left(x_{\max }-x_{\min }\right)
$$

where $x_{i}$ is the crisp value of the environmental variable for releve $i ; \mu\left(x_{i}\right)$ is the degree of belonging of relevé $t$ to the environmental fuzzy set corresponding to environmental variable $x$, and $x_{\max }$ and $x_{\min }$ are respectively the maximum and minimum values of the environmental variable.

2. Seven values, equidistant in the interval of variation of each environmental variable, are obtained as reference variable states using the formula (Cox 1994): 
Table 2. Averages of soil and of ground water variables for the associations.

\begin{tabular}{|l|c|c|c|c|}
\hline & Pucc.Halim & Pucc.Sarc & Pucc.Arth & Arth.Halo \\
\hline Ecs & 6.0 & 6.1 & 7.3 & 8.0 \\
PHs & 7.7 & 7.9 & 8.1 & 7.9 \\
Ts & 19.3 & 19.5 & 19.6 & 20.2 \\
Ecw & 20.2 & 27.5 & 20.6 & 33.3 \\
Tw & 19.5 & 19.5 & 20.0 & 19.2 \\
Hw & 3.9 & 9.0 & 5.4 & 10.4 \\
Sand\% & 6.9 & 4.2 & 2.7 & 0.9 \\
\hline
\end{tabular}

$S_{j}=x_{\min }+\left(x_{\max }-x_{\min }\right) *(j-1) / 6, \quad j=1, \ldots, 7$

where $S_{j}$ is the value of the environmental variable for the $j$-th state of reference, and $x_{\max }$ and $x_{\min }$ are the maximum and minimum values of environmental variable $x$.

3) For each of the seven variable reference states, the degree of belonging of each relevé is calculated using the crisp values of the single relevés (Formula 1).

According to Bezdek (1981), the function of belonging used is based on the distance between the value corresponding to the reference state and the crisp value of the single relevé:

$\mu_{i j}=\left(1 / D_{i j}\right)^{1 /(m-1)} / \sum_{j=1}^{7}\left(1 / D_{i j}\right)^{1 /(m-1)}$

where $\mu_{i j}$ is the degree of belonging of relevé $i$ to the $j$-th state of reference; $m=2 ; D_{i j}=\left(S_{j}-x_{i}\right)^{2} ; S_{j}$ is the value of the $j$-th variable state of reference, and $x_{i}$ is the value of variable $x$ for releve $i$.

4) The response function of each association with respect to the single environmental variable is modeled by averaging the degrees of belonging (Dubois and Prade 1987) of the relevés of the same association to the seven reference states:

$\mathbf{T}_{k}=\left\{\mu_{k j} \mid j=1, \ldots, 7\right\}$

where $\mathbf{T}_{k}$ is the vector of the average $\mu_{i j}$ values of the relevés in association $k$.

5) Linear interpolation is used to model the response of each association along the environmental gradients represented by each variable Cox (1994). The re- sponse function of each association to each environmental gradient is a curve of compatibility of the association with the environmental gradient (Bosserman and Ragade 1982, Dubois and Prade 1994).

To compare the response curves among associations, the amplitude is calculated by an arbitrary compatibility threshold (cut-off level) of 0.10 and an optimality threshold of 0.25 . The sequence of two compatibility curves (response functions) along a single gradient is determined for both thresholds according to:

curve $b$ follows curve $a$ if

$\max b+\min b>\max a+\min a$

where max and min identify the upper and lower values of the range of the single environmental factor with respect to each association.

\section{Results}

Models of the response of the plant associations to the environmental variables are summarized in Fig. 1. The curves fit the coenocline model of Whittaker (1967, 1975), since they are unimodal and generally have nonoverlapping maxima. Ranges corresponding to the two compatibility thresholds $(0.25$ and 0.10$)$ for each association with respect to the environmental variables are summarized in Table 3. The sequences of the response curves for each environmental variable, according to equation 4 and the sequence of averaged values, are shown in Table 4. The sequence of the averaged values accords well to the sequence of the association ranges, although there are some disagreements with the sequence of optima. Only two sequences are changed as the threshold changes from 0.10 to 0.25 . 
Table 3 may be used to predict the environment defined by the chosen environmental variables, both for compatibility and optimality. From this table, it is apparent that only association 4 (Arthrocnemo macrostachyi Halocnemetum strobilacei) has a distinct community niche (i.e., well separated from the other associations). The set of rules that can be extracted for environmental prediction based on the compatibility ranges are presented in Table 5. Similar rules can be obtained for the optimality range.

\section{Discussion}

Much work has been undertaken to demonstrate how plant associations can be defined and how they can be used for different purposes (e.g., land cover maps, landscape management, see Mucina 1997). While finding suitable hierarchies in ecological studies is important (Allen and Starr 1982), we recognize that much work is carried out at the population level, and that much of the ecological knowledge produced at the association level remains unexplored.
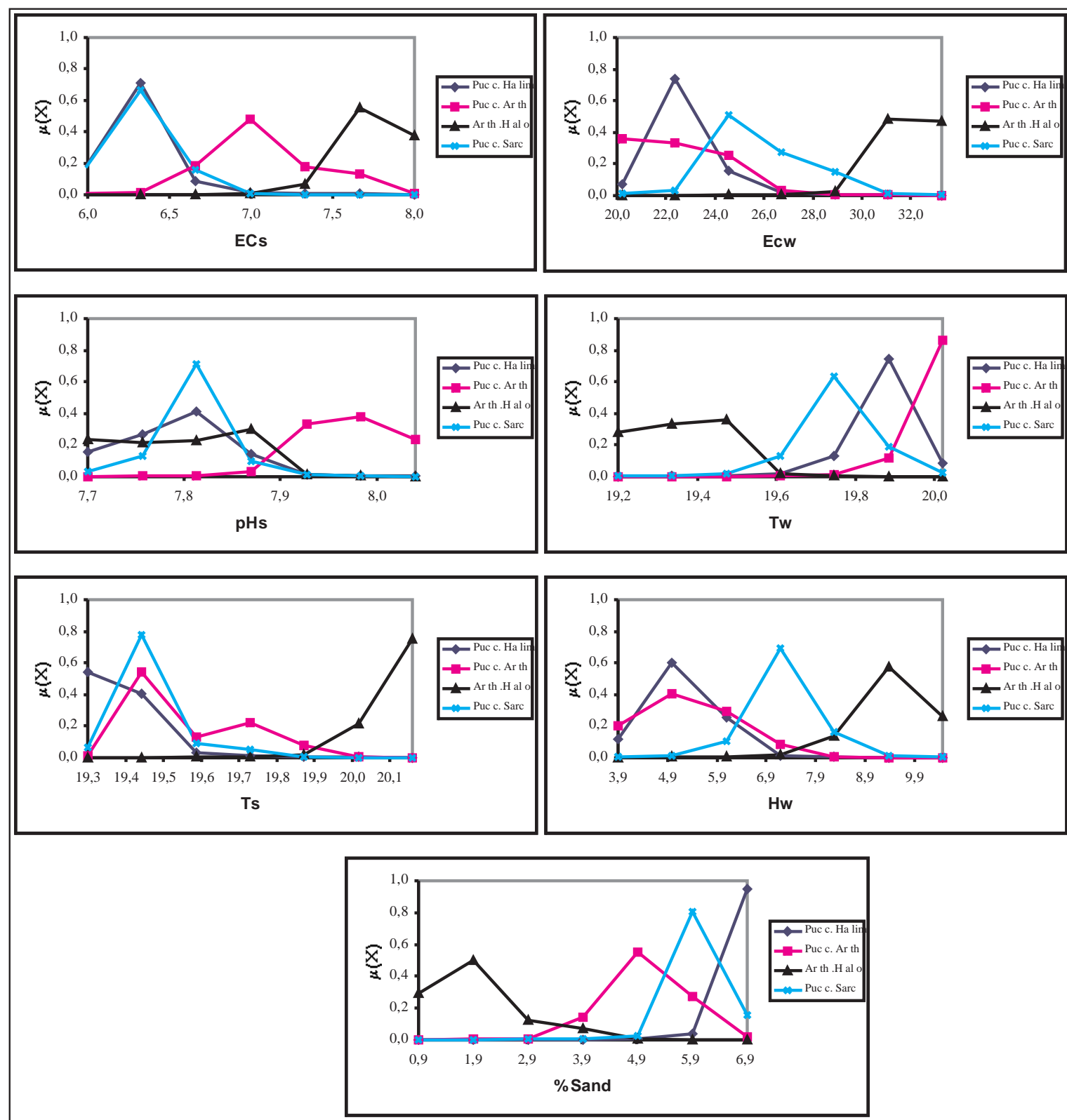

Figure 1. Fuzzy response curves of plant associations to environmental variables. 
Table 3. Ranges according to thresholds $(0.25$ and 0.10$)$ for each association with respect to all environmental variables.

\begin{tabular}{lcccccccc}
\hline & cut level & ECs & pHS & TS & ECW & Tw & HW & Sandz \\
\hline \multirow{2}{*}{ Pucc.Halim } & 0.10 & $5.99-6.65$ & $7.71-7.90$ & $19.30-19.56$ & $20.30-25.46$ & $19.66-19.97$ & $3.86-6.76$ & $6.00-6.94$ \\
& 0.25 & $6.04-6.57$ & $7.76-7.86$ & $19.30-19.50$ & $20.79-24.21$ & $19.72-19.94$ & $4.16-6.07$ & $6.17-6.94$ \\
Pucc. Sare & 0.10 & $5.99-6.78$ & $7.75-7.88$ & $19.31-19.58$ & $22.69-29.73$ & $19.52-19.91$ & $5.99-8.70$ & $5.02-6.94$ \\
& 0.25 & $6.04-6.60$ & $7.78-7.87$ & $19.34-19.55$ & $23.37-27.18$ & $19.59-19.81$ & $6.32-8.06$ & $5.22-6.80$ \\
Pucc.Arth & 0.10 & $6.50-7.75$ & $7.89-8.05$ & $19.32-29.85$ & $20.20-26.08$ & $19.81-19.97$ & $3.86-7.08$ & $3.61-6.62$ \\
& 0.25 & $6.74-7.25$ & $7.92-8.04$ & $19.36-19.55$ & $20.20-24.63$ & $19.86-19.97$ & $4.13-6.29$ & $4.19-6.03$ \\
Arth.Halo & 0.10 & $7.35-8.00$ & $7.71-7.92$ & $19.93-20.16$ & $29.24-33.25$ & $19.15-19.53$ & $7.90-10.43$ & $0.90-3.39$ \\
& 0.25 & $7.46-8.00$ & $7.84-7.89$ & $20.03-20.16$ & $29.96-33.25$ & $19.15-19.47$ & $8.52-10.43$ & $0.90-2.57$ \\
\hline
\end{tabular}

Table 4. Sequence of the response curves according to criterion 4. Cases: A) threshold equal to 0.1 ; B) threshold equal to 0.25 . Asterisks indicate difference between the sequences. C) indicates the sequence corresponding to average values in Table 2. Numbers within parentheses have the same average values in Table 2.

A)

\begin{tabular}{|l|l|}
\hline Sand\%: & \\
ECs: & \\
pHs: & \\
Ts: & \\
ECw: & \\
Tw: & \\
Hw: & \\
\hline
\end{tabular}

With

1 = Pucc.Halim; 2 = Pucc.Sarc; 3 = Pucc.Arth; 4 = Arth.Halo.
B)

\begin{tabular}{|c|c|c|c|c|c|c|c|c|c|}
\hline 4 & 3 & 2 & 1 & 4 & 3 & 2 & 1 & & $4 \begin{array}{lll}432 & 21\end{array}$ \\
\hline 1 & 2 & 3 & 4 & 1 & 2 & 3 & 4 & & 1234 \\
\hline 1 & 4 & 2 & 3 & 1 & 2 & 4 & 3 & * & $1\left(\begin{array}{ll}4 & 2\end{array}\right) 3$ \\
\hline 1 & 2 & 3 & 4 & 1 & 2 & 3 & 4 & & 1234 \\
\hline 1 & 3 & 2 & 4 & 3 & 1 & 2 & 4 & * & $\begin{array}{lll}13 & 2 & 4\end{array}$ \\
\hline 4 & 2 & 1 & 3 & 4 & 2 & 1 & 3 & & $4\left(\begin{array}{ll}2 & 1\end{array}\right) 3$ \\
\hline 1 & 3 & 2 & .4 & 1 & 3 & 2 & 4 & & 1324 \\
\hline
\end{tabular}

Numerical syntaxonomy (Mucina and Dale 1989), as defined by van der Maarel (1981), offers a framework for categorizing vegetation heterogeneity into plant associations defined by characteristic species combinations (Raabe 1952). These combinations are indicators of different environments, and can therefore be used as environmental predictors if it can be assumed that similar species compositions correspond to similar environments within a given geographical area. Feoli and Zuccarello (1988) proposed that syntaxonomy could be considered as a source of useful fuzzy sets for environmental analysis. Environmental fuzzy sets demonstrate the link between single relevés and single environmental variables by taking into account the similarities (degrees of belonging) of a single relevé to plant associations or other syntaxonomical units. If environmental fuzzy sets are used as ordination axes, one obtains a fuzzy ordination that is constrained by syntaxonomy (relevé classification). In the model proposed here, the environmental fuzzy sets are used as a basis for obtaining 'degree of belonging' curves for plant associations along environmental gradients. These curves, called compatibility curves in fuzzy set theory, can be used to model the response functions of plant associations along environmental gradients. Compatibil- ity curves indicate the similarity that a plant community (with a particular value of an environmental variable) has to the species combination of a given plant association.

Compatibility curves are an alternative approach to the non-linear regression and best fit analyses that are normally used to model single species responses to environmental gradients (Whittaker 1967, 1978, Austin 1976, 1987, 1990, ter Braak and Prentice 1988). This approach is particularly useful since there exists no mechanistic model that can capture the exact shape of the functional response along environmental gradients (Oksanen 1997, Bio et al. 1998), and because the environmental data are always affected by high noise level (Fulton 1996).

\section{Conclusion}

Using fuzzy set theory, we have demonstrated how response functions of different associations can be modeled along environmental gradients. The response functions can be used to define the community niche of plant associations based on ranges of compatibility and optimality. These ranges are used as the basis for deriving rules that can be used to predict the environment corresponding to plant associations found in the field. It is also possible to 
Table 5. Set of rules extracted from Table 3 for environmental predictions based on the compatibility ranges.

\begin{tabular}{|c|c|c|c|c|c|c|}
\hline If a plant community is assigned to & ECs & $\geq$ & 5.5 & and $\leq$ & 7 & and \\
\hline \multirow[t]{6}{*}{ Pucc.Halim then: } & $\mathrm{pHs}$ & $\geq$ & 7.5 & and $\leq$ & 8 & and \\
\hline & Ts & $\leq$ & 19.9 & & & and \\
\hline & $\mathrm{ECw}$ & $\leq$ & 26 & & & and \\
\hline & $\mathrm{Tw}$ & $\geq$ & 19.5 & & & and \\
\hline & $\mathrm{Hw}$ & $\leq$ & 7 & & & and \\
\hline & Sand\% & $\geq$ & 6 & & & \\
\hline If a plant community is assigned to & $\mathrm{ECs}$ & $\geq$ & 5.5 & and $\leq$ & 7 & and \\
\hline \multirow[t]{6}{*}{ Pucc.Sarc then: } & $\mathrm{pHs}$ & $\geq$ & 7.5 & and $\leq$ & 8 & and \\
\hline & Ts & $\leq$ & 19.9 & & & and \\
\hline & $\mathrm{ECw}$ & $\geq$ & 22 & & & and \\
\hline & $\mathrm{Tw}$ & $\geq$ & 19.5 & & & and \\
\hline & Hw & $\geq$ & 6 & and $\leq$ & 8 & and \\
\hline & Sand\% & $\geq$ & 5 & & & \\
\hline If a plant community is assigned to & $\mathrm{ECs}$ & $\geq$ & 6.5 & & & and \\
\hline \multirow[t]{6}{*}{ Pucc.Hart then: } & $\mathrm{pHs}$ & $\geq$ & 7.9 & & & and \\
\hline & Ts & $\leq$ & 19.9 & & & and \\
\hline & Ecw & $\leq$ & 27 & & & and \\
\hline & Tw & $\geq$ & 19.5 & & & and \\
\hline & $\mathrm{Hw}$ & $\leq$ & 7 & & & and \\
\hline & Sand\% & $<$ & 4 & & & \\
\hline If a plant community is a assigned to & Ecs & $\geq$ & 7 & & & and \\
\hline \multirow[t]{5}{*}{ Hart.Halo then: } & Ts & $>$ & 19.9 & & & and \\
\hline & Ecw & $\geq$ & 29 & & & and \\
\hline & Tw & $<$ & 19.5 & & & and \\
\hline & $\mathrm{Hw}$ & $>$ & 8 & & & and \\
\hline & Sand\% & $<$ & 4 & & & \\
\hline
\end{tabular}

define ranges at different thresholds of the response functions: by fixing higher thresholds, the 'kernel' of the community niche is approached. While potentially very useful in approximating prediction at various levels of precision, success clearly depends on data quality and quantity. The model presented here serves as a basis for further developments in the application of fuzzy set theory in vegetation ecology. In particular, it may be possible to develop fuzzy expert systems for environmental prediction based on the Braun-Blanquet synecology approach.

Acknowledgments: This work was supported by C.N.R. (grant No. AI94.00233.04). We are grateful to Prof. Rolando Calandra (University of Perugia) for the pedological analysis and his helpful suggestions. The assistance provided by Mrs Annamaria Vendramin and dr. Vincenzo Rossi (University of Ancona) is greatly appreciated. We thank two anonymous reviewers, and Professors J. Podani and N. Kenkel for linguistic correction and suggestions.

\section{References}

Allen, T.F.H. and T.B. Starr. 1982. Hierarchy: Perspectives for Ecological Complexities. The University Chicago Press, Chicago, London.

Andreucci, F., Biondi, E. and V. Zuccarello. 1999. La vegetazione alofila della Sacca di Bellocchio. Supplemento al Bollettino del Museo civico di Storia Naturale di Venezia 49: 143-168.

Austin, M.P. 1976. On non-linear species response models in ordination. Vegetatio 33: 33-41.

Austin, M.P. 1987. Models for the analysis of species response to environmental gradients. Vegetatio 69: 35-45.

Austin, M.P. 1990. Community theory and competition in vegetation. In: Grace J.B. and D. Tilman (eds.), Prespectives on Plant Competition. Academic Press, New York. pp. 215-235.

Bezdek, J. C. 1981. Pattern Recognition with Fuzzy Objective Function Algorithms. Plenum Press, New York.

Bio, A.M.F., Alkemade, R. and A. Barendregt. 1998. Determining alternative models for vegetation response analysis: a non-parametric approach. J. Veg. Sci. 9: 5-16. 
Biondi, E. 1992. The vegetation of sedimentary low coasts in Corfu island. Coll. Phytosoc. 19: 401-427.

Biondi, E. and M. Baldoni. 1994. Sul fitoclima della penisola italiana. Giorn. Bot. Ital. 128(1): 461.

Biondi, E. and M. Baldoni. 1995. A possible metod for geographic delimitation of phytoclimatic type: with application to the phytoclimate of the Marche region of Italy. Doc. Phytosoc. 15: 1528.

Bosserman, R.W. and R.K. Ragade. 1982. Ecosystem analysis using fuzzy set theory. Ecological Modelling 16: 191-208.

Braun-Blanquet, J. 1964. Pflanzensoziologie. Grundzuge der Vegetationskunde. 3. Aufl. Springer, Wien.

Brzezieki B., Kienast, F. F. and O. Wildi. 1993. A simulated map of the potential natural forest vegetation of Switzerland. J. Veg. Sci 4: 499-508.

Corbetta, F. 1976. Lineamenti vegetazionali della Sacca di Bellocchio (Foce del Reno). Ricerche di Biologia della Selvaggina 7 (Suppl. Scritti in memoria di Augusto Toschi): 247-270.

Cox, E. 1994. The Fuzzy Systems Handbook. Academic Press Inc., London.

Dubois, D. and H. Prade. 1987. Théorie des Possibilités. Masson, Paris.

Dubois, D. and H. Prade. 1994. Similarity-based approximate reasoning. In: Zurada J.M., R. J. Marks and C.J. Robinson (eds.), Computational Intelligence Imitating Life, IEEE Press, New York.

Egziabher T., E. Feoli, M. Fernetti, G. Oriolo and Z. Woldu. 1998. Vegetation mapping by integration of floristic analysis, GIS and remote sensing. An example from Tigray (Ethiopia). Plant Biosystems 132: 39-51.

Feoli, E. 1984. Some aspects of classification and ordination of vegetation data in perspective. Studia Geobotanica 4: 7-21.

Feoli, E. 1998. Exploring multidimensional space in vegetation science. In: E. Kazmierczak, A. Nienartowicz, A. Piernik and J. Wilkon-Michalska (eds.), Computer Methods in Investigation of the Structure and Functioning the Vegetation Cover. Wydaw, Uniw. Mikolaja Kopernika, Torun. pp. 143-156.

Feoli, E., P. Ganis and Z. Woldu. 1988. Community niche, an effective concept to measure diversity of gradients and hyperspaces. Coenoses 3: 79-82.

Feoli, E., M. Lagonegro and L. Orlóci. 1984. Information Analysis of Vegetation Data. Dr. W. Junk, The Hague.

Feoli, E. and V. Zuccarello. 1986. Ordination based on classification: yet another solution? Abstracta Botanica 10: 203-219.

Feoli, E. and V. Zuccarello. 1988. Syntaxonomy: a source of useful fuzzy sets for environmental analysis? Coenoses 3: 141-147.

Feoli, E. and V. Zuccarello. 1992. Fuzzy sets and structural changes in forest succession: an example from broad leaved forests of N.E. Italy. Coenoses 7: 81-90.

Fulton, M.R. 1996. An application of fuzzy set ordination to determine tree habitat suitability of sites from a regional data set. $J$. Veg. Sci. 7: 739-746

Greig-Smith, P. 1983. Quantitative Plant Ecology. 3rd ed. Blackwell, Oxford.
Mucina, L. 1997. Classification of vegetation: Past, present and future. J. Veg. Sci. 8: 751-760.

Mucina, L. and M.B. Dale (eds). 1989. Numerical Syntaxonomy. Kluwer, Dordrecht.

Mueller-Dombois, D. and H. Ellenberg. 1974. Aims and Methos of Vegetation Ecology. Wiley, New York.

Oksanen, J. 1997. Why the beta-function cannot be used to estimate skewness of species responses. J. Veg. Sci. 8: 147-152.

Orlóci, L. 1991a. Statistics in ecosystem survey: computer support for process-based sample stability tests and entropy/information inference. In: Feoli, E. and L. Orlóci (eds.), Computer Assisted Vegetation Analysis. Kluwer, Dordrecht. pp. 47-57.

Orlóci, L. 1991b. Poorean approximation and Fisherian inference in bioenvironmental analysis. Advances in Ecology 1: 65-71.

Orlóci, L. and V. De Patta Pillar. 1991. On sample size optimality in ecosystem survey. In: E. Feoli and L. Orlóci (eds), Computer Assisted Vegetation Analysis. Kluwer, Dordrecht. pp. 41-46.

Piccoli, F. 1995. Elementi per una carta della vegetazione del Parco del Delta del Po (Regione Emilia-Romagna). Fitosociologia 30: 213-219.

Pirola, A. 1959. Flora e vegetazione periglaciale sul versante meridionale del Bernina. Flora et Vegetatio Italica 1: 1-115. Gianasso, Milano.

Raabe, E.W. 1952. Über der "Affinitatswert" in der Pflanzensoziologie. Vegetatio 4: 53-68.

Rivas-Martinez, S. 1994. Clasificacion bioclimatica de la tierra. Folia Botanica Madritensis 11:1-20.

Rivas-Martinez, S. 1995. Clasificacion bioclimatica de la tierra. Folia Botanica Matritensis 16: 1-25.

ter Braak, C.J.F. and I.C. Prentice. 1988. A theory of gradient analysis. Adv. Ecol. Res. 18: 271-317.

van der Maarel, E. 1981. Some perspectives of numerical methods in syntaxonomy. In: H. Dierschke (ed.), Syntaxonomie. J. Cramer, Vaduz. pp 77-93.

Walter, H. 1979. Vegetation of the Earth and Ecological Systems of Geo-biosphere. 2nd ed. Springer-Verlag, New York.

Westhoff, V. and E. van der Maarel. 1978. The Braun-Blanquet approach. In: R. H. Whittaker (ed.), Classification of Plant Communities. 2nd ed. Junk, The Hague. pp. 287-399.

Whittaker, R.H. 1967. Gradient analysis of vegetation. Biol. Rev. 42: 207-264.

Whittaker, R.H. 1975. Communities and Ecosystems. Second Edition. Macmillan Publishing, New York.

Whittaker, R.H. 1978. Direct gradient analysis. In: R. H. Whittaker (ed.), Ordination of plant communities. Junk, The Hague. pp. 7-50.

Zadeh, L.A. 1965. Fuzzy sets. Inform. Control 8: 338-353.

Zimmerman, H. 1996. Fuzzy Set Theory and its Application. 3rd edition. Kluwer, Dordrecht.

Zuccarello, V., Allegrezza, M., Biondi, E. and R. Calandra. 1999. Valenza ecologica di specie ed associazioni prative e modelli di distribuzione lungo gradienti sulla base della teoria degli insiemi sfocati (Fuzzy Set Theory). Braun-Blanquetia 16: 121-226. 